\title{
HACIA UNA CLASIFICACIÓN DEL ESPACIO EN TEXTOS DE HORROR FANTÁSTICO
}

\author{
Cecilia Eudave \\ eudave850@hotmail.com \\ Universidad de Guadalajara
}

Recibido: 02-05-2018

Aceptado: 22-09-2018

(c) (1)

\section{RESUMEN}

En el presente artículo planteamos una propuesta teórico-analítica sobre la construcción del espacio en el horror fantástico, no desde la tipología del manejo de escenarios, o ambientaciones, sino que consideramos este espacio como una mediación estructural que nos prepara para abordar, desde otra focalización, los conflictos sociales, culturales o políticos. Planteamos tres tipos de divisiones espaciales: el espacio natural, el preternatural y el sobrenatural, tomando como punto de partida a autores en lengua inglesa que fueron señeros, como H. P. Lovecraft, con el fin de recalar en narradores mexicanos representativos del género. Tras los análisis pertinentes evidenciamos que el espacio preternatural es el más usual entre los escritores mexicanos y también, por extensión, entre los latinoamericanos.

PALABRAS CLAVE: horror, fantástico, espacio natural, espacio preternatural, espacio sobrenatural.

\section{TOWARDS A CLASSIFICATION OF SPACE IN FANTASTIC HORROR TEXTS}

\section{AbStRact}

In this article, we lay out a theoretical-analytical proposal regarding the construction of space in fantastic horror; not from the point of view of a typology of sceneries or environments, but as a structural mediation that paves the way to deal with social, cultural, and political conflicts from quite another perspective. Thus, we outline three sorts of spatial 
categories: the natural, the supernatural, and the preternatural spaces, and take incomparable English-speaking authors as a starting point, such as H. P. Lovecraft. Nonetheless, the aim is to turn to representative Mexican authors of the genre and demonstrate, after the relevant analysis, that the preternatural space is the most common among Mexican writers and, by extension, among Latin-Americans as well.

KEY WORDS: horror, fantastic, natural space, preternatural space, supernatural space.

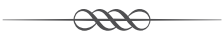

La preocupación por la materialidad del horror en la literatura ha sido una constante en todas las épocas y ha creado referencias comunes en las diferentes culturas. A pesar de que se puede representar de distintos modos, siempre se impone, en mayor o en menor grado, una proyección o refracción de los miedos más profundos de las sociedades en donde se gestan. La puesta en escena del horror no trae consigo ninguna inocencia, no interpela al lector como peón de una historia donde solo le pondrá los pelos de punta, sino que devela la parte más oscura de los discursos que generan la violencia comprometiendo su conciencia. Se genera una confusión que trae consigo un estar al límite de ciertos cuestionamientos sociales que emergen bajo la opacidad de un género aparentemente insólito, y nos expone a situaciones fuera del orden de lo común. Nos encontramos ante una palabra que con solo pronunciarla pone en marcha toda una maquinaria de representaciones de orden moral, ético, religioso, económico, político que transgreden realidades o las prefiguran para crear espacios donde vamos de la desestabilización al apocalipsis de los valores establecidos y sus formas.

El horror es difícil de aprehender, por eso va estableciendo sus dinámicas discursivas y sus propiedades estructurales de acuerdo al género que se apropie de él. Va de lo insólito a la realidad aparentemente más «verdadera», de lo confuso a la lucidez más escalofriante, resurgiendo y desembocando en problematizaciones que van desde lo sociológico, lo antropológico, lo psicológico o lo literario entre otros. El horror funciona en todos los niveles de construcción del texto como tema, como palabra-concepto, es decir, como signo de representación que lo limita y estandariza, o como motivo en la diégesis, todo lo cual lo hace objeto de discurso literario. Objeto que ofrece una perspectiva del mundo representado e interactúa con nosotros por medio de la escritura. 
Pero este horror como objeto concreto en la literatura necesita un lugar físico para manifestarse, para existir al ser enunciado.

Lo enunciado lleva a plantearnos el espacio como un lugar privilegiado para el tránsito y desarrollo del horror desde los planos de la realidad representada. Porque como dijera Michel Foucault en su Arqueología del saber -refiriéndose a la locura como objeto de discurso-, debemos localizar las superficies primeras de su emergencia, dónde surgen, cuáles son sus diferencias, para después designadas y analizadas, darnos cuenta de esas superficies de emergencia; es decir, el espacio en el que se posicionan y actúan, a sabiendas de que no son las mismas para cada sociedad, o época, y por lo cual se crean nuevas formas discursivas para enunciarlas (2002: 66-67).

Partiendo de lo expuesto, esta propuesta pretende un acercamiento a la prefiguración del horror fantástico desde la noción del espacio, y encuentra su detonante en la lectura de novelas de aparente corte realista que han prefigurado también las nociones del horror contemporáneo y su impacto en nuestras sociedades. Una de las más poderosas de entre ellas es El corazón de la tinieblas (1902), de Joseph Conrad. Ahí el espacio donde se desarrolla la historia que nos propone el autor no es nunca neutro, no es una escenografía para ubicar personajes y acciones sino que es vital, trasgresor y fronterizo; se aventura a transitar por los intersticios de la realidad — simbólica y ambigua-, y se vuelve sagrado, mítico, onírico o incluso fantástico en esa vorágine donde Kurtz y Marlow encontrarán la revelación. El primero la posee y la enuncia; el segundo la recibe y la comprende:

Él tenía algo que decir. Lo decía. Desde el momento en que yo mismo me asomé al borde, comprendí mejor el sentido de su mirada, que no podía ver la llama de la vela, pero que era lo suficientemente amplia como para abrazar el universo entero, lo suficientemente penetrante como para introducirse en todos los corazones que baten en la oscuridad. Había resumido, había juzgado. « El horror!» (2013: 111).

Sin detenernos a analizar otras implicaciones en el texto de Conrad, baste señalar para efectos de la propuesta que se presenta con relación al horror y el espacio que todo lo que hace el hombre está vinculado a la experiencia que se tenga con él, como bien lo señala Fernando Aínsa: «El espacio-tiempo es la propia experiencia, lo vivido, el lugar de la memoria y de la esperanza, y en la medida en que es posible representarlo, se puede reconstruir en la conciencia o simplemente recrearlo, crearlo, inventarlo en la ficción novelesca o poética» (2005: 47). Para Joseph Conrad el espacio de la vorágine en su bar- 
barie dio luz al espacio del horror desde su lectura civilizada del mundo. El horror pareciera oponer, se trate de una realidad fantástica o no, dos realidades, ya sean concretas o abstractas. Quizá porque como escribiera H. P. Lovecraft: «la incertidumbre y el peligro siempre andan estrechamente vinculados, formando de cualquier tipo de mundo desconocido un universo de amenazas y riesgos malévolos. $Y$ tan pronto como a esa sensación de temor y maleficencia se le agrega la inevitable fascinación de la maravilla y la curiosidad, entonces nace un sistema complejo de aguda emoción y de imaginativa excitación» (2002: 9). De ahí que los nativos vieran en Kurtz un Dios primitivo, salvaje, cruel como la naturaleza misma que los rodea: una selva semantizada como un espacio de horror y horrores, que a la postre quiere eliminarlos. Porque como bien lo señala Natalia Álvarez Méndez en su artículo «Hacia una teoría del signo espacial en la ficción narrativa contemporánea»:

Lo que posibilita esa impronta del espacio en la ficción es su carácter de signo, configurado por diferentes dimensiones (Camarero,1994: 92-93; Zumthor,1994: 347): la del espacio del discurso o significante, formado por el conjunto de signos que se conjugan en el discurso textual; la del espacio del objeto o referente, centrada en el lugar físico como objeto espacial que el escritor plasma en la obra literaria; y la dimensión del espacio de la historia o el significado, que es el que contiene la historia de la narración y el que posibilita que el escritor logre desarrollar el protagonismo y la significación simbólica de los diversos escenarios; sin dejar tampoco a un lado la olvidada dimensión del espacio de la lectura. Dado su carácter de signo, lo más justo es abarcar el espacio con todos sus valores sintácticos, semánticos y pragmáticos. Gracias a ellos se configuran sistemas sémicos en las narraciones y se organiza en cada obra un universo ficcional cuya coherencia es sometida por un peculiar código espacial determinante en el seno del discurso (2003: 551-552).

Por otra parte, el horror también es difícil de delimitar, se asocie a la literatura de corte realista o fantástica, porque es «emotivo, una masa aterradora que absorbe nuevas convenciones narrativas de cada cambio histórico o social. El horror siempre encuentra una nueva máscara terrorífica para hacer resonar preocupaciones actuales encontrando la cara oscura de cualquier deseo» (Sipos, 2010: 6); y se afinca, necesariamente, en el espacio exterior o interior de nuestra condición humana. Por ello, concordamos con lo que Stephen King señala en Danza macabra cuando diferencia entre el terror - cuyo efecto en el lector es gracias a lo sugerido y apela a su imaginación-, y el horror que, a diferencia de aquel, logra su eficacia en lo mostrado. El horror es explícito, debe ser físicamente perturbador. Y lo que nos interesa en este artículo es subrayar el horror como 
motivo para desplegar las distintas dimensiones que el espacio ofrece para acompañarlo, a veces explícitamente — apegada a lo fantástico- otras tantas de manera implícita, apenas sugerida, pero cobijado con un halo insólito que crea un efecto fantástico, como es el caso de El corazón de las tinieblas, mientras que el terror siempre necesita de cierta articulación espacial determinada y explícita. ${ }^{1}$

A partir de esas reflexiones me propuse intentar, no una tipología del manejo del espacio en el horror fantástico - escenarios, ambientaciones-, pero sí una posible lectura de la construcción del espacio, sus superficies de emergencia; es decir, cómo se programa en el texto discursivamente y nos prepara para percibir el horror, y desde ahí observar cómo se configuran las puestas en escena de los pavores sociales, culturales o políticos. El espacio será entonces una mediación entre los miedos ancestrales y los miedos modernos amparándose en un género narrativo; en este caso específicamente de lo fantástico. Esta propuesta, que es perfectible y está en etapa de desarrollo, gira en torno a la reflexión de tres divisiones espaciales que se deducen después de haber estudiado algunos relatos y que necesariamente, como toda clasificación, es arbitraria pero sirve para categorizar y organizar las inquietudes analíticas; estas son el espacio natural, el preternatural y el sobrenatural. No nos apegaremos al uso que se hace de estos términos en la teología, sino a su carácter más connotativo fuera del campo religioso ${ }^{2}$ y / o científico.

Existen trabajos de análisis que desde la perspectiva de lo preternatural y sobrenatural, particularmente, aplican estos términos a textos fantásticos en una lectura general, aquí solo se aplicará al tratamiento del espacio. Por ello es importante enfatizar que las observaciones irán únicamente en función de la configuración del espacio en cierto tipo de textos fantásticos del siglo xx. Con ello no queremos excluir otros relatos o novelas de distintas épocas a las

1 Al respecto nos apoyamos en las reflexiones de Natalia Álvarez Méndez, quien señala que: «atendiendo tanto a la dimensión del espacio del discurso como a la del referente, se advierte que el espacio cumple una importante función sintáctica en las tramas novelescas. Se aprecia su valor sintáctico desde el mismo momento en que, concibiéndolo desde un punto de vista exclusivamente ontológico, se asimila a un lugar físico, en el que se ubican los personajes y los acontecimientos. Además, al situar la acción, se convierte en uno de los elementos estructurantes de la sintaxis narrativa, constituyéndose en un soporte novelesco relevante en virtud de las relaciones establecidas entre los diversos escenarios de la historia. Este elemento despliega una destacada labor estructural y determina la sintaxis narrativa a través de la organización de los diversos desplazamientos, a la vez que vincula las formas a los sentidos. Por ello, el espacio, aunque construido en la narración por medio del lenguaje, es un componente de las circunstancias que rodean al ser humano y una realidad presente en el seno de la ficción. Así pues, es necesario atender también a otro tipo de valores, concretamente los semánticos, que condicionan y matizan la interpretación de la realidad del universo ficcional» (2003: 552).

2 Se pueden consultar las definiciones y diferencias de estos términos desde la óptica teológica consultando el libro Summa Daemoniaca. Tratado de demonología y manual de exorcistas, - bastante alucinante por cierto_ del teólogo y sacerdote español José Antonio Fortea, publicado en el 2007 por el Arzobispado de la Ciudad de México. 
cuales también podría atribuirse este manejo espacial propuesto. Finalmente, lo que generó esta posible clasificación es que consideramos el horror no solo como una emoción abstracta, sino que para poderse aprehender o generar catarsis debe responder a parámetros físicos y conformar una zona concreta por la que se desplace, sea a través de lo hiperbólico (la exageración del espacio amenazante), lo extrasensorial (la agudización extrema de los sentidos para distinguir otras realidades) y lo extralógico (aquello que supera las fronteras del raciocinio, del entendimiento). ${ }^{3}$

\section{EL HORROR EN EL ESPACIO NATURAL}

Esta modalidad espacial corresponde a lo que no quebranta el orden natural de las cosas. Nos referimos a un espacio ordinario - aunque a veces puede ser anodino o incluso exótico- pero que no rompe ninguna ley ni espacial ni temporal, ni de ambientación o escenificación. Sin embargo, no deja de ser poderoso en esa aparente convención y se maneja a varios niveles. El cuento de Shirley Jackson, «La lotería» (1948), por ejemplo, nos describe al detalle la cotidianeidad y geografía de un pueblo que cada año lleva a cabo un ancestral juego-ritual en el que participan todos los miembros de la comunidad. Consiste en sacar de una caja negra una papeleta, a la persona que le toque el papel marcado será lapidada por todo el pueblo; esto no implica para sus habitantes ningún problema, pese a que algunos ya comienzan a cuestionarse el rito y actúan en consecuencia con una normalidad aterradora, sazonada con bromas, anécdotas e inconformidades de los implicados:

—Bien, amigos — proclamó el señor Summers—, démonos prisa en terminar.

Aunque los vecinos habían olvidado el ritual y habían perdido la caja negra original, aún mantenían la tradición de utilizar piedras. El montón de piedras que los chicos habían reunido antes estaba preparado y en el suelo; entre las hojas de papel que habían extraído de la caja había más guijarros. La señora Delacroix escogió una piedra tan grande que tuvo que levantarla con ambas manos y se volvió a la señora Dunbar.

-Vamos -le dijo-. Date prisa (2015: 20-21).

3 Jaime Ricardo Reyes, en su libro Teoría de la didáctica del género del terror, propone estas características que atañen a las ambientaciones de relatos como los de Poe, las mismas que han sido tratadas con anterioridad por otros estudiosos del tema. Me parece pertinente aplicarlas a las reflexiones que se exponen en este trabajo, llevándolas más allá de los géneros literarios y sus convencionalismos, con el fin de ubicarlas en el manejo del espacio en textos que tienen como motivo el horror, aunque no sean necesariamente fantásticos, y así establecer un contrapunto de lectura. 
El horror que despierta su lectura es tan poderoso que crea un efecto que se acerca a lo fantástico deduciendo que hay una exageración, una especie de rasgo insólito ante la posibilidad de un comportamiento así. El espacio, ese pueblo anodino e insípido en apariencia, refuerza la perplejidad del lector develando ciertos horrores culturales y sociales muy perturbadores.

Otro ejemplo del manejo del espacio natural lo encontramos en el libro Por breve herida (2016) de Margo Glantz. El tema fundamental son los dientes y uno de los lugares privilegiados de la narración es la boca. Con el consabido estilo fragmentario, erudito y elegante de Glantz, nos introducimos en un recorrido no carente de ironías, historias sobre historias reales, otras fantásticas, de divagaciones y certezas que se conforman desde el perímetro íntimo o mínimo que es la boca, sea desde un punto de vista literal o metafórico. No es gratuito entonces que si vamos a hablar sobre el horror, la escritora decida abrir su libro tomando como referencia a Edgar Allan Poe al evocar «La caída de la casa Usher», y posteriormente «Berenice», seguido de otros hilos conductores como las pinturas de Bacon. Cito el inicio de esta novela híbrida, entre narrativa y ensayística, tan perturbador como inquietante:

Es difícil definir el horror. El gemido demente del terror (...) Pero en lugar de ahogar con su literalidad obsesiva el sentimiento brutal que intenta convocar, se alcanza una abstracción casi matemática, gracias a la repetición de la palabra horror, de la misma manera en que la repetida imagen de la boca abierta y dentada de Inocencio X, en la obra de Bacon (...) Subrayar la palabra con la exuberancia abusiva de su sonido podría ser simplemente cacofonía: en Poe, en cambio, se convierte bruscamente en metáfora que el abuso mismo hace aflorar: la angustia, el miedo se convocan en la raíz que los engendra (2016: 9).

La lectura de texto de Glantz demuestra que no hay espacio más temible que aquel que nos es obsesivo y propio, ese que está siempre ahí, inmutable, plano, acaso ya hasta imperceptible y que puede, sin embargo, en cualquier momento, sin poseer características sobrenaturales, desatar el horror llevándonos a evocar discursos que nos acerquen a los linderos de lo fantástico.

Lo anterior sirve para retomar El corazón de las tinieblas de Conrad, pues nos presenta otra variante del espacio natural. Siguiendo con estas reflexiones, la vorágine, esa selva y sus moradores, ese lugar que aunque sea exótico es ordinario en su contexto, va devorando al personaje, mimetizándolo al salvajismo adjudicado a este tipo de áreas, reforzando su patología, desenmascarando su verdadero yo: el de un occidental apegado a las ideas colonialistas, cegado por la industria y el dinero, que se asume como un dios destructor. Los 
espacios, entonces, adquieren connotaciones insólitas, semejantes a un infierno en la tierra en el que anidan los horrores construidos por un ser humano que desbordó los límites de lo posible. En esta novela encontramos cómo los personajes se vinculan poderosamente al espacio, y este «se convierte en un signo que remite mediante procesos metonímicos y metafóricos a la situación de los caracteres novelescos, a sus sentimientos, ideas o acciones. De tal modo, (...) que el marco en el que se mueve el personaje es expresión de su propia figura y llega incluso, en ocasiones, a modelarle» (Álvarez Méndez, 2003: 553554). Así, el espacio del horror natural se ubicaría esencialmente en la zona concreta de lo hiperbólico comprometiendo nuestro asombro a una realidad que ya no nos parece tan lógica y ordenada, prefigurando el comportamiento de los actantes y nuestra lectura.

\section{EL ESPACIO DEL HORROR PRETERNATURAL}

La definición de este concepto gira en torno a un espacio llevado «más allá» del universo material. Esta modalidad espacial se prefigura fuera de su contexto, o estado natural, y excede las posibilidades de su naturaleza ordinaria sin que necesariamente cree mundos sobrenaturales. Como bien lo expresa Rosalba Campra en su libro Territorios de la ficción. Lo fantástico, podríamos decir que la percepción de los personajes - y agregamos el espacio donde se desarrollará la trasgresión del espacio que habita- es la que determina la organización a nivel semántico de cualquier objeto de discurso en el género de lo fantástico:

Y es ahí donde se insinúa la duda sobre el efectivo acontecer del hecho fantástico. Dado que el universo del relato lo define como imposible, el lector puede preguntarse si su realización debe ser atribuida a un verdadero trastrocamiento del orden natural o más bien a la percepción distorsionada de quien es su protagonista y testigo. Desde este punto de vista, el problema se plantea como consecuencia de la reducción de nuestro concepto de realidad a la realidad percibida. Se trata pues de una parcialidad recortada por las posibilidades de los sentidos humanos (2008: 85-86).

Siguiendo la reflexión por parte de la teórica argentina, podemos sugerir, desde esta propuesta de lectura, que el espacio preternatural, específicamente, determina la percepción de la realidad textual. Este opera como mediador de realidades, ya que el territorio, tanto físico como discursivo, donde 
se desarrolla la diégesis (selvas, bosques, pueblos, casas decadentes, el metro, una pecera, una estación de ferrocarril, la boca o el cuerpo mismo como lugar para lo insólito), determina la perspectiva, no solo del personaje sino del lector, acercándolo o alejándolo de su idea de lo real, de lo posible. El espacio no solo superpone órdenes aparentemente irreconciliables sino que compromete nuestra perspectiva de los mismos porque todo lo que sucede ahí es «verdad aunque se trate de verdades discrepantes» (Campra, 2008: 87).

Siendo el espacio preternatural uno de los más utilizados por los escritores del siglo xx y xxI, y a partir del estudio de algunos textos, se proponen las siguientes variantes. La primera sería la transposición: un espacio ordinario que se pervierte y que es remplazado por otro de apariencia fantástica con el fin de propiciar el estado extrasensorial de los personajes, reforzando el horror, no a lo desconocido sino a aquello real que presentimos como una amenaza. Hay una serie de encadenamientos ambientales o escenográficos que determinan el comportamiento del sujeto en el texto y, desde ahí, se fincan principalmente las problemáticas de orden existencial por cierto tipo de presión social.

La escritora mexicana Amparo Dávila usa con frecuencia esta variante para reforzar el motivo del horror en sus cuentos. Por ejemplo, «La celda», incluido en Tiempo destrozado (1959), es uno de sus relatos más celebrados. La historia da cuenta de una joven que no puede cancelar el eminente matrimonio arreglado por la familia, ni decirles el motivo por el cual no puede acceder a sus deseos. La razón fantástica, con la que se encubren otras razones reales, es que a ella la posee físicamente por las noches un ente maligno que además la retiene en una celda llena de cadáveres, de moscas y de ratones. Con el paso de los días, y ya con el matrimonio más cerca, ella se encierra en su habitación de la casa paterna, ahora pervertida o suplantada por sus aparentes delirios y que resulta ser una celda en el castillo del ser acosador después de haber puesto fin al destino pactado por su familia:

¡Qué cuarto tan frío y oscuro!, tan oscuro que el día se junta con la noche; ya no sé cuándo empiezan ni cuándo terminan los días; quiero llorar de frío, mis huesos están helados y me duelen; siempre estoy subida en la cama, amonigotada, cazando moscas, espiando a los ratones que caen irremediablemente en mis manos; el cuarto estálleno de cadáveres de moscas y ratones, huele a humedad y a ratones putrefactos, pero no me importa, que los entierre otro, yo no tengo tiempo; este castillo es oscuro y frío como todos los castillos: yo sabía que él tenía un castillo... iqué lindo estar prisionera en un castillo, qué lindo!; siempre es de noche; y él no deja que nadie me vea; mi casa ha de estar muy lejos (...) ¿dónde está mamá y Clara? Clara es mi hermana mayor; iyo no las quiero, les tengo miedo, que no vengan, que no vengan...! Tal vez ya están muertas y 
tienen los ojos abiertos y brillantes como los tenía José Juan aquella noche; yo quería cerrarle los ojos porque me daba miedo que me estuviera viendo; tenía los ojos muy abiertos y muy brillantes... «serás una bella novia, toda blanca» (2003: 57).

Una segunda variante en relación a este apartado consiste en los desplazamientos espaciales que dan paso a planos temporales distintos: pasar del presente al pasado, o viceversa, o del presente al futuro. Aquí el personaje o narrador adjudica a una alucinación pasajera o a factores externos inusuales la recepción de otra realidad paralela pero que finalmente no encuentra una explicación convincente. Como ejemplos proponemos el cuento «La cena» (1912), de Alfonso Reyes, y la novela corta Aura (1962), de Carlos Fuentes. En ambos textos los personajes son invitados a dejar sus planos temporales para habitar otros. Tanto Alfonso como Felipe Montero, respectivamente, ingresan al espacio estático y perturbador de una casa, con dos mujeres como anfitrionas, una joven, la otra mayor. La casa, poco a poco, se convierte en el espacio de una revelación terrible al confrontarlos con su verdadero yo: ambos son hombres de formación militar, muertos hace tiempo, que deben reconocerse y abandonar sus identidades actuales para recuperar la del pasado.

En el caso de la novela Aura el motivo del horror se desarrolla puntualmente en varias direcciones; no solamente en el rechazo al presente en busca de un pasado idílico, sino el terror a envejecer y el tópico del amor eterno muy propio de las narraciones del siglo xIX:

Sabes al cerrar de nuevo el folio, que por eso vive Aura en esta casa: para perpetuar la ilusión de juventud y belleza de la pobre anciana enloquecida. Aura, encerrada como un espejo, como un icono más de ese muro religioso, cuajado de milagros, corazones preservados, demonios y santos imaginados (Fuentes, 2001: 42).

Este tipo de manejo espacial en los dos textos está completamente encadenado al «tiempo detenido» que David Roas expone como «una variante que para ser percibida (y comprendida) también necesita de la comparación entre ese tiempo que experimenta el protagonista y el tiempo "real", "objetivo". Ahí es donde se produce la transgresión fantástica» (2012: 109). En ambos textos los personajes no se liberarán del horror que experimentan hasta que acepten su verdadero yo, solo entonces podrán ser restituidos a su espacio — este es el caso de Alfonso-, o absorbidos por el espacio, lo que le sucede a Felipe Montero.

La tercera y última variante, por ahora propuesta, correspondería a la de dos o más espacios que se superponen aunque pertenezcan a realidades distintas y convivan en uno mismo que, sin ser necesariamente fantástico, se convier- 
te en tal por la imposible compatibilidad entre uno y otro. El relato «Fiesta brava» (1972), de José Emilio Pacheco, da cuenta de este tipo de manejo espacial: tres planos de realidad se superponen y con ello se logra crear el efecto fantástico. El primero de ellos es el de boletín de búsqueda — que provoca la impresión de la extratextualidad - con el que se inicia el relato indicando que se gratificará a quien proporcione informes sobre Andrés Quintana, quien se ha extraviado. El segundo plano es el literario: al doblar la hoja el lector lee el cuento «Fiesta brava» del escritor desaparecido. En esta historia redactada por Quintana ya encontramos una serie de elementos de horror relacionados con el mundo prehispánico mexicano, pues se acaba sacrificando a su personaje, un veterano de la guerra de Vietnam, el capitán Keller, a manos de unos hombres que siguen rituales aztecas en zonas ocultas del metro de la Ciudad de México.

El tercer plano de la historia corresponde al momento de la redacción del texto: el lector descubre que este cuento se lo pidieron por encargo a Quintana y debe entregarlo un día después de haberlo terminado. El manuscrito es rechazado por parte de la revista de carácter internacional, sufragada por los Estados Unidos, aludiendo que es un «maquinazo» que recuerda a muchos textos con ese tema, entre ellos «La noche bocabajo» de Julio Cortazar y «Huitzilopochtli» de Rubén Darío, a lo que Quintana responde: «Ya todo está escrito cada cuento sale de otro cuento» (1997: 94). Dicho esto, Andrés abandona el edificio y se dirige al metro con la sensación de que ya todo eso lo ha vivido, hace el trayecto de costumbre y justo, como en su relato, y al bajar del metro distingue entre los últimos pasajeros a un gringo que le resulta familiar, es el capitán Keller, y ambos se reconocen con desconcierto:

Bajó en la estación de Insurgentes. Los magnavoces anunciaban el último viaje de esa noche. Todas las puertas iban a cerrarse. De paso leyó una inscripción grabada a punta de compás sobre un anuncio de Coca Cola: asesinos, no olvidamos Tlatelolco y san Cosme./ debe decir: «ni San Cosme»,/ corrigió Andrés mientras avanzaba a la salida. Arrancó el tren que iba en dirección de Zaragoza. Antes de que el convoy adquiriera velocidad, Andrés advirtió entre los pasajeros del último vagón a un hombre de camisa verde y aspecto norteamericano.

El Capitán Keller ya no alcanzó a escuchar el grito que se perdió en la boca del túnel (1997: 98).

El texto de Pacheco superpone los espacios de la ficción y la realidad en el vagón del metro, como si toda realidad respondiera a la misma realidad, como cada cuento sale de otro cuento. Los tres planos de la historia, desde distintos momentos temporales, ayudan a borrar las fronteras espaciales y tan- 
to el escritor como el personaje de su cuento corren la misma suerte a manos de la violencia que imaginada o no es equivalente. Considero que al utilizarse este manejo espacial los textos no se apegan a un fantástico convencional sino que se convierten en un juego de analogías sociales que dan paso a un sistema alegórico de la realidad. El horror es el absurdo, el desorden, el caos, la atrocidad política, el yugo moral, etc. La pérdida del orden, sobre todo social, genera miedo y devela las problemáticas de una sociedad a diferentes niveles.

Por otra parte, encuentro que el espacio del horror preternatural es reiterativamente utilizado por los narradores hispanoamericanos, pues han encontrado en él una manera de denunciar las atrocidades nacionales cobijándose bajo el halo de lo fantástico, de lo imposible, de lo aparentemente insólito. Así lo hace Juan José Arreola en «El guardagujas» (1952) donde se evidencia el caos ferroviario posrevolucionario, último vestigio de comunicación y orden del Porfiriato; mientras que Salvador Elizondo, en «Ambystoma Tigrinum» (1972), ensaya la construcción de un espacio posible y terrible: Axolotitlán, la gran ciudad de los ajolotes, resultando esto una analogía del mexicano del siglo xx, siempre eludiendo el rechazo y en busca de su identidad. De igual modo logran sustituir las ambientaciones y espacios fantásticos del imaginario europeo o colonial español para generar otros que les son más próximos. Los lugares anodinos o cotidianos son el receptáculo para la acción, estos autores los llevan al límite, al extremo, creando así otra tipología espacial que genera una nueva conciencia de la ambientación fantástica: la selva en Horacio Quiroga, las casas «tomadas» de Julio Cortazar, las bibliotecas y los laberintos mentales de Jorge Luis Borges, los objetos en Guadalupe Dueñas, los pueblos rurales de Juan Rulfo y Elena Garro, por solo mencionar algunos ejemplos.

El espacio del horror preternatural, además de ser hiperbólico, se adhiere a lo extrasensorial agudizando realidades que no son sino analogías sociales que denuncian los miedos más próximos, los que respiran detrás de nuestra nuca aunque les demos la espalda. Y prefiguran una nueva variante escenográfica para el drama de lo fantástico acompañado de motivos distintos, en este caso el horror, y que fortalecen los mecanismos de lo insólito; más allá de ambientar crean una atmósfera de trasgresión propicia para la ambigüedad -herencia semántica de la tradición que le precede- que facilita lo preternatural, espacio que fragiliza las fronteras entre realidades posibles en el universo verosímil de los textos que pertenecen a géneros de carácter especulativo. 
Nos referimos a aquellos espacios que desafían cualquier creación posible en el marco de la realidad convencional. Universos autónomos cuya lógica de construcción rebasan los límites de la compresión y nos obligan a recurrir a un nuevo sistema de interpretación para asirlos y/o entenderlos; lugares fuera de los planos dimensionales de la realidad pactada. En la tradición de lo sobrenatural el mundo de los muertos y sus horrores se inscribiría aquí, y todas las variantes de los infiernos, sus estados intermedios, necrópolis, limbos y demás derivados se ampararían en este apartado.

Uno de los grandes creadores de lo sobrenatural, que da una vuelta de tuerca al horror, es sin duda Lovecraft. Creador de dimensiones inexploradas en las que habitan seres milenarios que ya no proceden del imaginario religioso conocido, y que tienen como fin crear una teogonía propia con base en los mitos de Cthulhu. Para explicar los orígenes del horror crea deidades, criaturas milenarias dispuestas a arrasar la humanidad e imponer sus principios; con ello devela la verdadera naturaleza dormida en el hombre, es decir, su proclive fascinación hacia el mal, las perversiones más abominables por medio de una sacralidad abyecta. Todo esto no tendría el mismo efecto si las ambientaciones, los espacios cuidadosamente confeccionados para ser los escenarios del horror, no impactaran directamente en el lector sobrepasando su capacidad para asirse a cualquier lógica posible.

Lovecraf logra que la noción del «más allá» pierda sus fronteras de cara a la tradición que lo precede. Cito a continuación un ejemplo entrecortado del texto El que susurra en la oscuridad (1930), fragmento citado en el libro Bestiario:

Hay ciudades poderosas en Yuggoth: grandes hileras de torres con terrazas de piedra negra como la muestra que traté de enviarle. Provenía de Yuggoth. Ahí el sol no brilla más que una estrella, pero los seres no necesitan luz. Tienen otros sentidos más sutiles, y no ponen ventanas en sus casas o templos. La luz incluso los daña, los molesta y los confunde, pero no existe en absoluto en el cosmos negro fuera del tiempo y el espacio de que son originarios. Visitar Yuggoth volvería loco a cualquier hombre débil; sin embargo me dirijo ahí. Los ríos negros de brea que fluyen sobre misteriosos puentes ciclópeos — construidos por alguna raza anterior ya extinta y olvidada antes de que los seres actuales llegaran a Yuggoth desde los vacíos actuales - tendría que bastar para hacer de cualquier hombre un dante o un Poe sólo con que pudiera mantenerse cuerdo el tiempo suficiente para contar lo que ha visto. Pero recuerde: ese mundo oscuro de jardines fungiformes y ciudades sin ventanas no es realmente terrible. Sólo a nosotros nos lo parecía (2008: 13). 
Así como Lovecraft es ya un referente en la construcción de mundos y espacios sobrenaturales, en México tenemos a un escritor singular ubicado entre los más raros exponentes de la literatura insólita: Emiliano González. Tomaré, para ejemplificar, El discípulo. Una novela de horror sobrenatural (1989), contenida en el volumen Casa de horror y magia del mismo año. Esta novela corta envuelve a sus personajes en una serie de situaciones que desencadenan una alucinante historia y reproducen muchas de las características de la literatura decadentista a la que González es afecto. Aurelio Summers, protagonista principal de la narración, escribió un manuscrito en Londres, a manera de diario, relatando su experiencia preparatoria antes de ser absorbido por el universo de La Gran Esfera. Un universo atroz, delirante, y casi imposible de describir.

El manuscrito fue rescatado por un abad de las manos de una secta que adoraba ese libro como si se tratara de escrituras sagradas, y aquel se vuelve su custodio hasta la llegada del narrador de la historia: un investigador literario que buscaba datos de Summers y que termina escribiendo su experiencia. El citado investigador tiene acceso al texto donde se expone cómo Aurelio cortejará a Maisie, mujer misteriosa y oscura que lo llevará a sus límites para entrar en contacto con la perversión y las anarquías sociales. Ella lo guiará hasta La Gran Esfera, legado de su padre, que les desvelará sus personalidades ocultas —él, un sátiro; ella, una mona blanca-, además de revelarles su destino: ser eternos y habitar los distintos planos de la realidad que contiene la esfera. En la novela se insiste en que «El mal es relativo. Dios no lo ha creado; lo ha tolerado; para indicar a los hombres la ausencia de luz, para estimularlos en la búsqueda de la pureza. Ergo: el mal es sagrado. El Mal no fue creado: ha existido siempre, pero no de manera metafísica» (1989: 27).

La parte que más nos interesa para hablar de espacio sobrenatural es la del manuscrito, está dividido en tres momentos: la escritura verde, donde se explica que ha decidido consagrarse «al estudio de la estética, al delittanismo y a esas ciencias ocultas que nadie entiende» (1989: 21). La escritura sepia, donde comienza la iniciación de Aurelio Summers de la mano de Maise para acceder al universo de la esfera que abre puertas dimensionales y muestra, como hemos dicho, el yo verdadero: «la puerta se abre durante diez segundos, hacia un lugar que, a pesar de existir en la realidad... jno os corresponde! La puerta conduce a Gales, a una época futura y al horror. ¡Cuidado con la frágil puerta!» (1989: 38). Finalmente, la escritura negra, la del espacio detenido, donde no se envejece y se es espectador de los delirios propios y ajenos. Un mundo en el centro de la tierra que enloquece a Summers e impide descifrar al investigador las últimas páginas del diario porque se han vuelto ilegibles. A partir de 
aquí la narración se torna delirante y llena de evocaciones a espacios alucinados. Aurelio acaba asumiendo la imagen que La Gran Esfera le ha otorgado: la de un sátiro; después de la aceptación de su verdadero yo se desencadenan una serie de enumeraciones espaciales sin aparente sentido:

Metamorfosis- pantano- mi reloj estalla- selva amazónica- «un éxtasis que provoca dios»- un dios que provoca un sapo- (aquísiguen garabatos incomprensibles)«se hincha de anhelo»- «aparece Dios»- gran rey sapo- el discípulo vomita amor- la Gran Sabiduría- Maisie- la esfera- pesadilla de amor- las uñas del ilobate en la espalda del sátiro- las uñas- religión de sapos- vómito místico- Metamorfosis- el pantano de cópulas trigonocéfalo verde gigantesco- (1989: 45).

Destaquemos también en este relato los diferentes planos narrativos a nivel de construcción de espacios. Mientras en el manuscrito se describen las distintas dimensiones; en la narración de la novela se realiza desde dos planos espaciales: el primero el del investigador y el Abad leyendo a Summers; el segundo, Aurelio y su siniestro destino esférico que lo somete y domina. Tanto dimensiones como planos espaciales se articulan al horror sobrenatural que unifica las realidades contrapuestas en el universo de La Gran Esfera irremediablemente diabólica.

Como se puede observar, los espacios sobrenaturales arrasan con la comprensión y la razón previamente anclada, su espacio es extralógico, y no pueden sino orillarnos a la emoción más que a la intelectualización de lo narrado. La atmosfera desasosegante imposibilita el anclaje en razonamientos convencionales, quedamos varados en mundos concebidos como espacios que desafían las leyes inflexibles de nuestra realidad.

\section{CONCLUyendo}

Somos conscientes de que esta mínima clasificación tiene como fin establecer un diálogo entre los distintos usos que se le da al espacio en relación con el género fantástico donde el motivo del horror se finca fundamentalmente entre lo preternatural y lo sobrenatural. En cambio, el espacio del horror natural se inserta en el discurso de lo fantástico o insólito, no como género sino como una enunciación más próxima a lo simbólico y a lo mítico.

Consideramos que el manejo espacial, sobre todo preternatural, en textos de horror-fantástico o en textos fantásticos en general del siglo xx y del XXI, han encontrado en él un aliado para desmontar las historias, convirtiéndose 
no solo en escenarios que acompañan lo narrado sino en generadores de significación. Es decir, el espacio rompe, transgrede, desestabiliza, irrumpe, nos prepara para lo fantástico aun en su aparente neutralidad. La construcción de lugares asumidos como anodinos o de lugares comunes que se transitan todos los días logran desestabilizar y a su vez crear una extrañeza que es capaz de confundir y sobresaltar porque rompe con los estereotipos y confronta nuestra conciencia. Conciencia que se ve comprometida desde el espacio en el que se enfrenta a lo fantástico orillándonos a buscar nuevas perspectivas para asir representaciones menos estandarizadas de las realidades sociales que nos circundan. De este modo se establecen distintos planos de comunicación desde lo espacial —insistimos—que nos aproximan a una nueva configuración de horizontes metafóricos, alegóricos o de analogías que, en su naturaleza polisémica, nos orientan hacia lo que subyace en este tipo de texto: denuncias de las atrocidades del mundo contextual del que proceden.

Para finalizar esta propuesta sobre el espacio en textos fantásticos que se centran en el horror, retomemos uno de los argumentos que Lovecraft registra en su libro El horror sobrenatural en relación a las atmósferas, donde insiste en que son «el elemento más importante, por cuanto el criterio final de la autenticidad no reside en urdir una trama, sino en la creación de una impresión determinada» (2002:11). Ello se debe a que estos relatos nos devuelven el miedo más primario y fundamental, ahí donde la racionalidad no es suficiente para adentrarse en la condición humana. Tal vez porque cuando los leemos nos descubrimos a nosotros mismos como el espacio más fértil e ideal para el horror y la monstruosidad.

\section{BiBLIOGRAFÍA}

AínSA, Fernando (2005): Espacio literario y fronteras de identidad, Editorial Universidad de Costa Rica, Costa Rica.

Álvarez MÉnDEz, Natalia (2003): «Hacia una teoría del signo espacial en la ficción narrativa contemporánea», Signa. Revista de la Asociación Española de Semiótica, núm. 12, pp. 540-570.

Arreola, Juan José (1972): Bestiario, Editorial Joaquín Mortiz, Ciudad de México.

CONRAND, Joseph (2013): El corazón de las tinieblas, Editorial Juventud, Barcelona.

CAmpra, Rosalba (2008): Territorios de la ficción. Lo fantástico, Editorial Renacimiento, Sevilla.

DÁvila, Amparo (2003): Tiempo destrozado, Editorial FCE, Ciudad de México.

Elizondo, Salvador (2000): El grafógrafo, Editorial FCE, Ciudad de México. 
ForTEA, José Antonio (2007): Summa Daemoniaca. Tratado de demonología y manual de exorcistas, Editorial El arca, Ciudad de México.

Foucault, Michel (2002): La arqueología del saber, Editorial Siglo XXI, Buenos Aires.

Glantz, Margo (2016): Por breve herida, Editorial Sexto Piso, Ciudad de México.

Fuentes, Carlos (2001): Aura, Editorial ERA, Ciudad de México.

GonZÁlez, Emiliano (1989): Casa de horror y magia, Editorial Joaquín Mortiz, Ciudad de México.

JACKSON, Shirley (2015): La lotería, Editorial Penguin Random House, Ciudad de México. KING, Stephen (2006): Danza macabra, Editorial Valdemar, Madrid.

Lovecraft, H. P. (2002): El horror sobrenatural en la literatura, Editorial Fantamara, Ciudad de México.

- (2008): Bestiario, Editorial Libros del Zorro rojo, Madrid-Barcelona.

PACHeCo, José Emilio (1997): El principio del placer, Editorial ERA, Ciudad de México.

REYES, Alfonso (2014): Obras completas III, Editorial FCE, Ciudad de México.

REYES, Jaime Ricardo (2006): Teoría y didáctica del género del terror, Editorial Magisterio, Bogotá.

RoAs, David (2012): «Cronologías alteradas. La perversión fantástica del tiempo», en Flavio García y María Cristina Batalla (coords.), Vertentes teóricas e ficcionais do Insólito, Editora Caetés, Río de Janeiro (Brasil), pp. 106-113.

SIPOs, Thomas M. (2010): Horror film aesthetics. Creating the visual Languague of fear, Editorial McFarland \&Company, Jefferson, NC. 